\title{
Endoscopic Removal of Small Gastrointestinal Stromal Tumors: Can We GIST-ify the Risk?
}

\author{
Christopher A. Marshall • Benjamin J. Hyatt • \\ Wahid Wassef
}

Published online: 29 April 2010

(C) Springer Science+Business Media, LLC 2010

\section{Background}

GISTs are the most common subepithelial tumor of the stomach with a prevalence of 129 per one million [1]. Nearly 500-600 new cases are diagnosed per year in the United States according to the Surveillance, Epidemiology, and End Results (SEER) program of the National Cancer Institute's (NCI) report in 1995 [2]. More recently, including incidental findings, it is estimated that there are 3,000-6,000 new cases per year in the United States [3]. As more of these lesions are found, a strategy to manage these will need to be developed. A recent AGA technical review suggests observation for GISTs less than $3 \mathrm{~cm}$ without high risk features [4].

In this month's issue of Digestive Diseases and Sciences, Bai et al. present an interesting article on the endoscopic removal of small GIST tumors $(<30 \mathrm{~mm})$ [5]. While the authors report a technical success with removal, we should be asking ourselves "should we," rather than "can we." To answer this question, we need to have a better understanding of the diagnosis, prognosis, and management of these lesions.

\section{Diagnosis}

The diagnosis of GIST is often made after EUS referral for the evaluation of subepithelial lesions. Its diagnostic yield can vary. It can be as low as $68.7 \%$ (range 40-100\%) without tissue acquisition and as high as $84 \%$ (range $73.8-$

C. A. Marshall $(\bowtie) \cdot$ B. J. Hyatt · W. Wassef

Division of Gastroenterology, University of Massachusetts

Medical School, Worcester, MA, USA

e-mail: marshc01@ummhc.org
$100 \%$ ) with tissue acquisition [6]. Unfortunately, even though the diagnosis can be obtained by EUS, predicting its course is not as easy. Although many studies demonstrate features that suggest malignant GISTs on EUS (size $>3 \mathrm{~cm}$, irregularity of the extraluminal border, presence of cystic spaces, echogenic foci, and heterogeneity), inter-observer variability is high and results can vary $[4,7,8]$.

\section{Outcomes}

Two bodies of evidence demonstrate that small gastric GISTs are benign and have a low rate of metastases and progression: resection studies and natural history studies.

We know from a variety of long-term studies of resected GISTs that outcomes and recurrence rates are based upon size, location, and mitotic rate. In a series of 127 patients of surgically resected GISTs by DeMatteo et al., benign outcomes were prognosticated by: size $<5 \mathrm{~cm}$, mitotic rate of $<5 / \mathrm{hpf}$, and gastric location [9]. These findings were confirmed in a literature review by Miettinen and Lasota where small GISTs of gastric location carry an excellent prognosis [3] (Table 1).

More information on the natural history of GISTs can be glistened from natural history studies of small GISTs that are not removed [7, 10-12]. Studies by Gill et al. and Chien et al. and have shown that the majority of subepithileal tumors $<3 \mathrm{~cm}$ including GISTs do not change in size with a mean follow-up of 20.7 and 23 months, respectively $[7,10]$. In another longitudinal study with a mean followup of 16.5 months (range 5-114), 30\% (6/20) of patients with $19 \mathrm{~mm}$ (10-32 mm) GISTs had a decrease in tumor size by $1-5 \mathrm{~mm}, 40 \%(8 / 20)$ had an increase in tumor size by $2-21 \mathrm{~mm}$, and $30 \%(6 / 20)$ remained stable [13]. Other studies have demonstrated similar results. Lachter et al. 
Table 1 Progressive disease in gastric GIST

\begin{tabular}{lll}
\hline Tumor size & Mitotic rate & $\begin{array}{l}\% \text { With progressive } \\
\text { disease (risk) }\end{array}$ \\
\hline$\leq 2 \mathrm{~cm}$ & $\leq 5$ per $50 \mathrm{hpf}$ & None (very low) \\
& $>5$ per $50 \mathrm{hpf}$ & None (very low) \\
$>2 \mathrm{~cm}$ and $\leq 5 \mathrm{~cm}$ & $\leq 5$ per $50 \mathrm{hpf}$ & 1.9 (very low) \\
& $>5$ per $50 \mathrm{hpf}$ & 16 (moderate) \\
$>5 \mathrm{~cm}$ and $\leq 10 \mathrm{~cm}$ & $\leq 5$ per $50 \mathrm{hpf}$ & 3.6 (low) \\
& $>5$ per $50 \mathrm{hpf}$ & 55 (high) \\
$>10 \mathrm{~cm}$ & $\leq 5$ per $50 \mathrm{hpf}$ & 12 (moderate) \\
& $>5$ per $50 \mathrm{hpf}$ & 86 (high)
\end{tabular}

Adapted from Miettinen et al. [3]

demonstrated that of 70 patients with $23.2 \mathrm{~mm}$ GISTs, only $20 \%$ of cases increased in size by more than $2 \mathrm{~mm}$. They also found that the risk for enlargement was related to initial tumor size $>17 \mathrm{~mm} \quad(P=0.018)$ [14]. These observations are confirmed in several other small studies $[11,12]$.

In this article, Bai et al. present the management of 25 patients with small gastric GISTs $(<30 \mathrm{~mm})$ [5]. Based on resection and natural history studies in the literature and even histologic evaluation of the data of Bai and colleagues, these types of lesions are benign. Therefore, there seems to be no clear medical indication for their removal unless the proposed intervention aimed at their removal is safe and effective.

\section{Management}

Currently, the standard of care for GIST removal is surgery. It is well tolerated with little morbidity for tumors $<10 \mathrm{~cm}$ [2]. In a recent study of laparoscopic resections of GISTs, tumors $>2 \mathrm{~cm}$ were removed with very little morbidity (1 patient with leak at suture line) and no deaths $(n=35)$. The hospital stay was reasonable with an average of only 7-8 days [15]. This is similar to other published data on laparoscopic resection with a technical success of $98.3-100 \%$ and a length of stay of 3.9-7.2 days [16]. These results are certainly acceptable for high risk lesions, but do not seem to be indicated for low risk lesions. Bai et al., in their study, try to find a safer way for the effective removal of the smaller, low risk lesions with a shorter hospital stay. His technique, although effective, is not low risk. His study reports a $28 \%$ perforation rate (up to $6 \mathrm{~mm}$ in size) leading to a prolonged hospital stay (4.28 days) [5]. This figure is significantly higher than ESD (endoscopic submucosal dissection) done for other indications. For example, in a large Japanese study where ESD is performed for the resection of another type of gastric lesion (early gastric cancer) the overall perforation rate was $4 \%$ with low rates of bleeding and no cases requiring surgery [17]. In another study, reported by a Korean multicenter group, the perforation rate was even lower (1.2\%) [18]. The differences can be attributed to the pathology of the lesion being treated. For instance, GISTs emerge from the muscle layer of the stomach and, therefore, would be expected to have a higher perforation rate than gastric neoplasms which are mucosal, allowing for a safer dissection and resection. Clearly, this difference in histopathology would make one hesitate in performing this type of a procedure for these benign lesions.

\section{Conclusions}

The endoscopic removal of small GISTs by ESD is technically feasible as demonstrated in the article by Bai et al. [5]. Its use, though, cannot be justified given that it carries a $28 \%$ perforation rate along with a potential prolonged hospital stay (4.26 days) for a very benign condition. Therefore, until safer technology becomes available for endoscopic removal of GISTs, the best approach would still be that of watchful waiting for small, low risk GISTs and laparoscopic removal for those that are high risk based on size, location and mitotic rate.

\section{References}

1. Hyatt BJ, Paull PE, Wassef W. Gastric oncology: an update. Curr Opin Gastroenterol. 2009;25:570-578.

2. Chaudhry UI, DeMatteo RP. Management of resectable gastrointestinal stromal tumor. Hematol Oncol Clin North Am. 2009; 23:79-96.

3. Miettinen M, Lasota J. Gastrointestinal stromal tumors: pathology and prognosis at different sites. Semin Diagn Pathol. 2006; 23:70-83.

4. American Gastroenterological Association Institute. Technical review on the management of gastric subepithelial masses. Gastroenterology. 2006;130:2217-2228.

5. Bai J, Wang Y, Guo H, Zhang P, Ling X, Zhao, X. Endoscopic resection of small gastrointestinal stromal tumors. Dig Dis Sci. doi:10.1007/s10620-010-1168-7.

6. Scarpa M, Bertin M, Ruffolo C, Polese L, D'Amico DF, Angriman I. A systematic review on the clinical diagnosis of gastrointestinal stromal tumors. J Surg Oncol. 2008;98:384-392.

7. Gill KRS, Camellini L, Conigliaro R, et al. The natural history of upper gastrointestinal subepithelial tumors: a multicenter endoscopic ultrasound survey. J Clin Gastroenterol. 2009;43: 723-726.

8. Shah P, Gao F, Edmundowicz SA, Azar RR, Early DS. Predicting malignant potential of gastrointestinal stromal tumors using endoscopic ultrasound. Dig Dis Sci. 2009;54:1265-1269.

9. Dematteo RP, Gold JS, Saran L, et al. Tumor mitotic rate, size, and location independently predict recurrence after resection of primary gastrointestinal stromal tumor (GIST). Cancer. 2008; 112:608-615. 
10. Chien $\mathrm{CH}$, Chien RN, Yen CL, et al. The role of endoscopic ultrasonography examination for evaluation and surveillance of gastric subepithelial masses. Chang Gung Med J. 2010;33:73-81.

11. Lok KH, Lai L, Yiu HL, Szeto ML, Leung SK. Endosonographic surveillance of small gastrointestinal tumors originating from muscularis propria. J Gastrointest Liver Dis. 2009;18:177-180.

12. Bruno M, Carucci P, Repici A, et al. The natural history of gastrointestinal subepithelial tumors arising from muscularis propria: an endoscopic ultrasound survey. $J$ Gastrointest Liver Dis. 2009;43:821-825.

13. Maor Y, Avidan B, Melzer E, Bar-Mier S. Long-term clinical outcome of patients with gastric gastrointestinal stromal tumors. Dig Dis Sci. doi:10.1007/s10620-009-1107-7.

14. Lachter J, Bishara N, Rahimi E, Shiller M, Cohen H, Reshef R. EUS clarifies the natural history and ideal management of GISTs. Hepatogastroenterology. 2008;55:1653-1656.
15. Sasaki A, Koeda K, Obuchi T, et al. Tailored laparoscopic resection for suspected gastric gastrointestinal stromal tumors. Surgery. 2010;147:516-520.

16. Sexton JA, Pierce RA, Halpin VJ, et al. Laparoscopic gastric resection for gastrointestinal stromal tumors. Surg Endosc. 2008; 22:2583-2587.

17. Hotta K, Oyama T, Akamatsu T, et al. A comparison of outcomes of endoscopic submucosal dissection (ESD) for early gastric neoplasms between high-volume and low-volume centers: multicenter retrospective questionnaire study conducted by the Nagano ESD study group. Intern Med. 2010;49:253-259.

18. Chung IK, Lee JH, Lee SH, et al. Therapeutic outcomes in 1000 cases of endoscopic submucosal dissection for early gastric neoplasms: Korean ESD study group multicenter study. Gastrointest Endosc. 2009;69:1228-1235. 